\title{
Congenital Hypothyroidism: A Review of 2020 European Society for Pediatric Endocrinology and the European Society for Endocrinology Consensus Guidelines
}

\section{Catherine E. Kerr and Gary L. Francis}

Division of Endocrinology; Department of Pediatrics; University of Texas Health Science Center San Antonio; San Antonio, Texas, U.S.A.

Review of: van Trotsenburg AS, Stoupa A, Léger J, Rohrer TR, Peters C, Fugazzola L, Cassio A, Heinrichs C, Beauloye V, Pohlenz J, et. al. 2020 Congenital hypothyroidism: A 2020 consensus guidelines update An ENDO-European Reference Network (ERN) initiative endorsed by the European Society for Pediatric Endocrinology and the European Society for Endocrinology. Thyroid. Epub 2020 Dec 3. PMID: 33272083.

\section{SUMMARY}

\section{Background}

Newborn screening for congenital hypothyroidism $(\mathrm{CH})$ identifies one affected infant from every 2000-3000 live births. Effective screening programs facilitate early recognition and treatment that have almost eliminated developmental delay and have optimized outcomes. Unfortunately, 70\% of infants worldwide are born in areas without access to newborn screening programs. The most sensitive test for the detection of primary $\mathrm{CH}$ is measurement of the serum thyrotropin (TSH) level. Early treatment and close monitoring to normalize TSH throughout infancy and childhood are essential.

This publication by the European Paediatric Endocrine Society and the European Society for Endocrinology (1) is an updated version of the $\mathrm{CH}$ guidelines published by the European Society for Paediatric Endocrinology in 2014 (2). Other professional organizations have also published guidelines, including the Japanese Society for Pediatric Endocrinology (3) and the American Academy of Pediatrics (4).

\section{Methods}

Twenty-two panelists were selected from ENDO-ERN representing the European Paediatric Endocrine Society and the European Society for Endocrinology. They were divided into five working groups: neonatal screening, diagnosis and criteria for treatment, treatment and monitoring, outcomes, and genetics of $\mathrm{CH}$ and antenatal management. Starting in 2017, panelists spent 24 months reviewing articles published in English after 2013 and ranked their recommendations according to the GRADE system (grading of recommendations, assessment, development, and evaluation) (5). Both the strength of the recommendation (strong = applies to most patients; weak = depends on patient circumstances) and the quality of the evidence (low = case series; moderate $=$ indirect evidence or studies with methodologic flaws; high = low risk for bias) were provided for all recommendations.

\section{Recommendations}

The main points of the guidelines include that abnormal $\mathrm{CH}$ screening results should be confirmed 
PEDIATRIC THYROIDOLOGY Congenital Hypothyroidism: A Review of 2020 European Society for Pediatric Endocrinology and the European Society for Endocrinology Consensus Guidelines
Catherine E. Kerr and Gary L. Francis by measures of serum free thyroxine $\left(\mathrm{FT}_{4}\right)$ and TSH. CH is stratified into mild ( $\left.\mathrm{FT}_{4}, 10-15 \mathrm{pmol} / \mathrm{L}\right)$, moderate $\left(\mathrm{FT}_{4}, 5-10 \mathrm{pmol} / \mathrm{L}\right)$, and severe $\left(\mathrm{FT}_{4},<5\right.$ $\mathrm{pmol} / \mathrm{L})$ categories and is treated with 10-15 $\mu \mathrm{g}$ of levothyroxine per kilogram of body weight per day. The $\mathrm{FT}_{4}$ should be normalized as soon as possible and the TSH within 4 weeks of life.

Treatment with levothyroxine ( $\mathrm{L}_{\mathrm{T}} \mathrm{T}_{4}$; usually 10-15 $\mu \mathrm{g} / \mathrm{kg} /$ day) should begin if the $\mathrm{FT}_{4}$ is low and the TSH is greater than the age-adjusted range or if the serum $\mathrm{TSH}$ is $>20 \mathrm{mU} / \mathrm{L}$ (beyond 1 week of age) even if $\mathrm{FT}_{4}$ is normal; or if the serum TSH remains above $6 \mathrm{mU} / \mathrm{L}$ beyond 21 days of age. The first aim of treatment is to achieve TSH in the normal range for age. The second goal is to maintain $\mathrm{FT}_{4}$ in the upper half of the normal range for age. Treatment for central hypothyroidism (CH of pituitary or hypothalamic origin) should begin after finding evidence of normal adrenal function or after glucocorticoid replacement. Diagnostic isotope scanning and ultrasonography (dual imaging) should be performed prior to the 5 th day of $\mathrm{L}-\mathrm{T}_{4}$ treatment, but should not delay treatment.
Genetic testing facilitates diagnosis and focused genetic counseling. All newborns with $\mathrm{CH}$ should be screened for birth defects (especially cardiac) and hearing loss. Many babies have an increased risk for false-negative $\mathrm{CH}$ screening results, including preterm, low-birth-weight (LBW) and very low-birthweight (VLBW) infants, same-sex twin of an affected proband, and patients with Down syndrome. For these newborns, a second screening at approximately 10 to 14 days of age is recommended. Developmental progress and hearing should be regularly assessed, and eventual transition to adult care should be organized.

\section{Conclusions}

Early diagnosis and treatment of $\mathrm{CH}$ optimize developmental outcomes. Important questions remain regarding genetic etiology, the increasing incidence of $\mathrm{CH}$, possible harm from untreated subclinical hypothyroidism (normal $\mathrm{FT}_{4}$ with elevated $\mathrm{TSH}$ ), and optimal screening for babies in intensive care.

\section{COMMENTARY}

This newest guideline (1) expands previous recommendations regarding $\mathrm{CH}$ screening, rapid treatment, and judicious monitoring (2-4). The new recommendations inform best practices and illuminate areas in need of additional study, including:

1. For infants without access to serum $\mathrm{FT}_{4}$ measurement, ${\mathrm{L}-\mathrm{T}_{4}}_{4}$ should be started if $\mathrm{TSH}$ is $>40$ $\mathrm{mU} / \mathrm{L}$ on filter paper testing.

2. During treatment, an $\mathrm{FT}_{4}$ above normal may be acceptable if the TSH is in the age-adjusted normal range and no symptoms occur.
3. $L-\mathrm{T}_{4}$ can be administered with food as long as the time and relation to food are consistent from one day to the next.

4. Liquid ${\mathrm{L}-\mathrm{T}_{4}}_{4}$ is an acceptable alternative to crushed tablets, as opposed to ${\mathrm{L}-\mathrm{T}_{4}}_{4}$ suspensions.

5. Thyroid nodules and cancers may develop in patients with $\mathrm{CH}$ caused by dyshormonogenesis. They should maintain a low-normal TSH and undergo periodic ultrasound. 
PEDIATRIC THYROIDOLOGY Congenital Hypothyroidism: A Review of 2020 European Society for Pediatric Endocrinology and the European Society for Endocrinology Consensus Guidelines
Catherine E. Kerr and Gary L. Francis
6. Genetic testing by comparative genomic hybridization, next-generation sequencing, or whole-exome sequencing should be performed to better inform the diagnosis and future management. This guideline (1) provides an excellent summary of known mutations resulting in $\mathrm{CH}$, and recommendations for genetic counseling.

7. Treatment of pregnant women with hypothyroidism should include an increase of the $\mathrm{L}_{4} \mathrm{~T}_{4}$ dose, monitoring of $\mathrm{FT}_{4}$ and TSH every 4 to 6 weeks, and maintenance of TSH $<2.5 \mathrm{mU} / \mathrm{L}$. In women with central hypothyroidism, the goal of therapy should be to maintain the $\mathrm{FT}_{4}$ above the mean or median trimester-specific value.

8. Fetal goiter should prompt consideration for NKX2-1 mutations associated with increased mortality.

However, several issues lack harmonization and remain to be addressed, including the following:

- Persistent mild CH. In a 2018 survey of newborn screening programs in the United States, vastly different screening protocols were reported.
Of the 51 programs surveyed, 14 included a routine second screen, and 28 included a repeat filter paper test of the TSH if the initial screen returned a result of "borderline increased TSH" (6). Furthermore, almost half of the programs ( 24 of 51) did not use age-adjusted TSH reference values, including 8 programs that performed routine second screening and 16 programs that performed a second screen for a borderline initial test. This practice results in more false-negatives, and mild persistent $\mathrm{CH}$ could be missed. However, the neurodevelopmental consequences of untreated mild persistent $\mathrm{CH}$ are unknown.

- Screening for CH in LBW and VLBW infants in the neonatal intensive care unit (NICU). In 2016, a Japanese survey found that $65 \%$ of NICUs commonly performed simultaneous serum $\mathrm{FT}_{4}$ and $\mathrm{TSH}$ measurements for infants $<1500$ grams (7). Only $29 \%$ used criteria to begin $\mathrm{L}-\mathrm{T}_{4}$ treatment, and those criteria varied from 15-30 $\mathrm{mU} / \mathrm{L}$ for $\mathrm{TSH}$ and $<0.5$ to $<0.7 \mathrm{ng} / \mathrm{dl}$ for $\mathrm{FT}_{4}$. Additional work is needed to define appropriate screening strategies, outcomes, and goals for this population.

\section{References}

1. van Trotsenburg P, Stoupa A, Léger J, Rohrer TR, Peters C, Fugazzola L, Cassio A, Heinrichs C, Beauloye V, Pohlenz J, et. al. 2020 Congenital hypothyroidism: A 2020 consensus guidelines update An Endo-European Reference Network (ERN) initiative endorsed by the European Society for Pediatric Endocrinology and the European Society for Endocrinology. Thyroid. Epub 2020 Dec 3.
2. Léger J, Olivieri A, Donaldson M, Torresani T, Krude H, van Vliet G, Polak M, Butler G 2014 European Society for Paediatric Endocrinology consensus guidelines on screening, diagnosis, and management of congenital hypothyroidism. J Clin Endocrinol Metab 99:363-384. 
PEDIATRIC THYROIDOLOGY Congenital Hypothyroidism: A Review of 2020 European Society for Pediatric Endocrinology and the European Society for Endocrinology Consensus Guidelines
Catherine E. Kerr and

Gary L. Francis
3. Mass Screening Committee, Japanese Society for Pediatric Endocrinology, Japanese Society for Mass Screening, Nagasaki K, Minamitani K, Anzo M, Adachi M, Ishii T, Onigata K, Kusuda S, Harada S, Horikawa R, Minagawa M, et al. 2015 Guidelines for Mass Screening of Congenital Hypothyroidism (2014 revision). Clin Pediatr Endocrinol 24:107-133.

4. Rose SR, Brown RS, Foley T, Kaplowitz PB, Kaye $\mathrm{Cl}$, Sundararajan S, Varma SK 2006 Update of newborn screening and therapy for congenital hypothyroidism. Pediatrics 117:2290-2303.

5. Swiglo BA, Murad MH, Schunemann HJ, Kunz R, Vigersky RA, Guyatt GH, Montori VM 2008 A case for clarity, consistency, and helpfulness: State-ofthe-art clinical practice guidelines in endocrinology using the grading of recommendations, assessment, development, and evaluation system. J Clin Endocrinol Metab 93:666-673.

6. Kilberg MJ, Rasooly IR, LaFranchi SH, Bauer AJ, Hawkes CP. 2018 Newborn screening in the US may miss mild persistent hypothyroidism. J Pediatr 192:204-208.

7. Uchiyama A, Sugihara S, Kusuda S. 2016 National survey on concepts for congenital hypothyroidism screening in neonatal intensive care units in Japan. Pediatr Int 58:1311-1315.

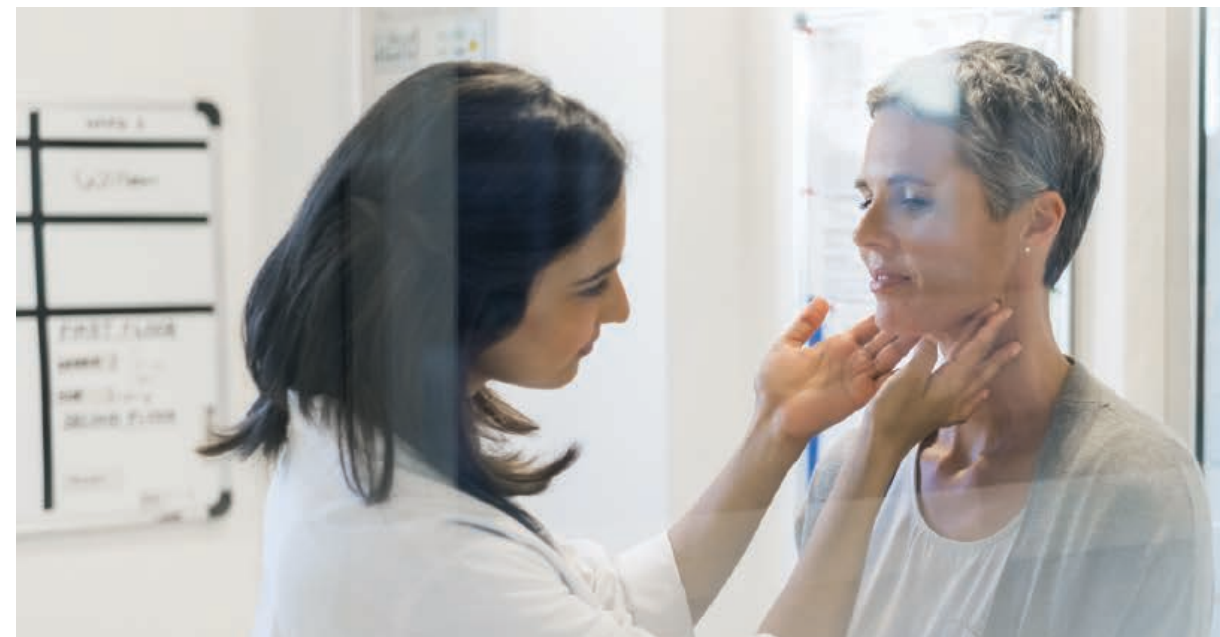

Make ATA your professional home. Access high quality publications, register for education at members-only rates, and participate in career development sessions Join today and save!

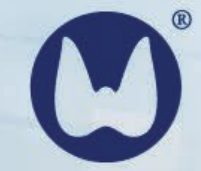

A M E R I C A N

THYROID ASSOCIATION

Optimal Thyroid Health for All 